\title{
Emulsion liquid membrane extraction and determination of cefadroxil with cyanex301 as an extractant
}

\author{
*Saira Mulla, , Suhas Kulkarni, Anand C. Patil \\ *Asst. Professor in Department Of Chemistry, N.G. Acharya \& D.K. Marathe College of arts science \& \\ commerce, Chembure, Mumbai,
}

\begin{abstract}
A novel method for the emulsion liquid membrane extraction and separation of antibiotic cefadroxil from $1 \times 10^{-2} \mathrm{~mol} / \mathrm{dm}^{3} \mathrm{HCl}$ feed phase using cyanex301 has been developed. Cefadroxil has been stripped from organic phase with carbonate buffer of pH 9.0 and determined spectrophotometrically at $230 \mathrm{~nm}$. The method developed has been applied for the selective separation of cefadroxil from synthetic industrial effluent. The method developed is rapid, simple and excels most of the conventional techniques because of following merits such as low energy requirements, compact modular device, simultaneous extraction and stripping in the same device, zero pollution and use of mild to moderate process conditions. The method developed is reproducible with a relative standard deviation of $0.42 \%$.
\end{abstract}

Keywords: Emulsion liquid membrane, Cefadroxil, Cyanex301.

\section{Introduction:}

Antibiotics are produced by semisynthetic and enzymatic fermentation processes. Separation and purification of these antibiotics specially present in the mother liquors after the recovery of major amounts by conventional filtration or extraction procedure is not cost effective instead labor intensive by current techniques. Separation of these from dilute solutions in presence of fermentation broth is necessary in industries. Emulsion Liquid Membrane (ELM) technique is very effective and efficient for the separation of such solutes specially from dilute solutions. Amberlite LA-2 ${ }^{(1)}$, D2EHPA ${ }^{(2)}$, Aliquat- $336^{(3)}$ and Alamine- $336^{(4)}$ have been used as mobile carriers in ELM. Effective separations of antibiotics such as penicillin $-G^{(5)}$, cephalosporin-C and cephalexin $^{(3)}$ by ELM have been studied, but separation of antibiotic such as cefadroxil (7-[Amino-(4hydroxyphenyl)acetyl]-amino]-3-methyl-8-oxo-5-thio-1-azabicyclo[4.2.0]oct-2-ene-2-carboxylicacid

monohydrate ${ }^{(6)}$,cefadroxil is antibacterial used in treatment of mild to moderate infections caused due to susceptible microorganism ${ }^{(7)}$ have not been studied by ELM technique. We therefore, report herein a method which is more advantageous than other conventional techniques due to zero pollution, smaller volume of raffinate and flexibility of operation.It also gives satisfactory recovery from synthetic industrial effluent samples.

\section{Experimental}

A UV-visible(160-A) recording spectrophotometer(Shimadzu), control dynamic pH meter equipped with a combined glass electrode and magnetic stirrer, high speed homogenizer(Remi, India) were used for the absorbance and $\mathrm{pH}$ measurement and transport studies respectively.

Stock solution of standard cefadroxil $\left(1 \mathrm{mg} / \mathrm{cm}^{3}\right)$ was prepared by dissolving $100 \mathrm{mg}$ standard cefadroxil in $100 \mathrm{~cm}^{3}$ distilled water and working solution $\left(50 \mu \mathrm{g} / \mathrm{cm}^{3}\right)$ were prepared by suitable dilution of stock solution in distilled water. Span-80(S.D.Fine Chemicals Ltd.), Cyanex-301(American Cyanamide Co.) and Aliquat336(Fluka Chemie AG) were used as supplied. All other chemicals such as toluene, sodium citrate, citric acid, sodium carbonate, sodium chloride and $\mathrm{HCl}$ were of AR grade.

Preparation of membrane- $13 \mathrm{~cm}^{3}$ span- $80+10 \mathrm{~cm}^{3}$ of Cyanex-301 diluted to $100 \mathrm{~cm}^{3}$ with toluene. $10 \mathrm{~cm}^{3}$ of internal phase carbonate buffer of $\mathrm{pH} 9.0$ was added to a $5 \mathrm{~cm}^{3}$ of membrane stirred vigorously on magnetic stirrer for 20 minutes to get stable milky white emulsion. $15 \mathrm{~cm}^{3}$ of emulsion prepared was added into $100 \mathrm{~cm}^{3}$ beaker, containing $50 \mathrm{~cm}^{3}$ of $1 \times 10^{-2} \mathrm{~mole} / \mathrm{dm}^{3} \mathrm{HCl}$ with $50 \mu \mathrm{g}$ cefadroxil and the contents were stirred gently at 300rpm on a magnetic stirrer for a given transfer time of 25 minutes. The emulsion was separated using a separating funnel and broken down(de-emulsified) by treating it with $0.5 \mathrm{~cm}^{3}$ of butanol. Cefadroxil so separated in the aqueous phase is estimated spectrphotometrically at $230 \mathrm{~nm}^{(4)}$. Mass transfer was calculated from the percentage of cefadroxil in the organic phase. 


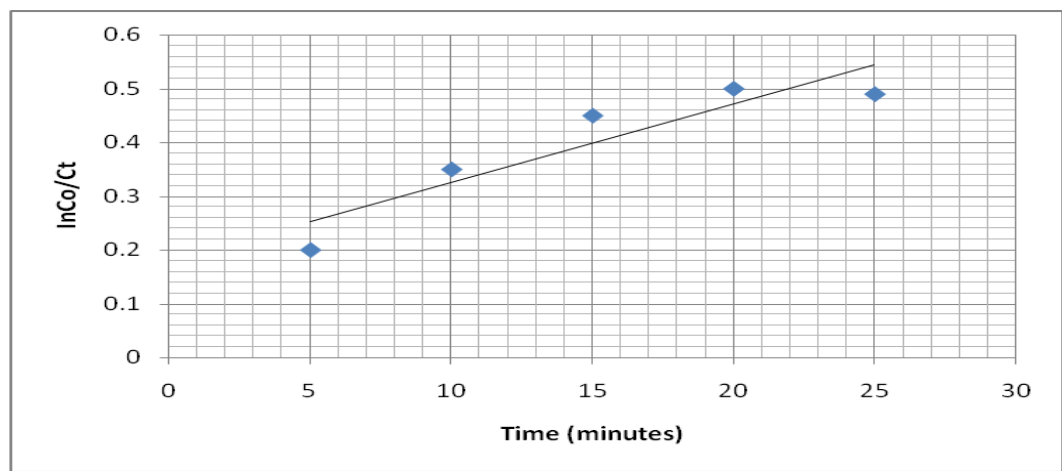

Fig.1.1 Kinetic curve of transport of cefadroxil through ELM process

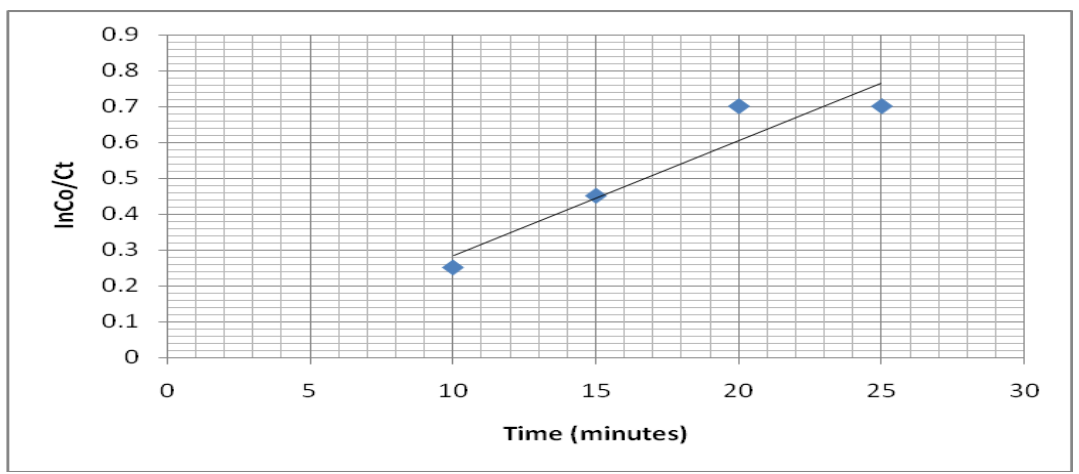

Fig.1.2 Kinetic curve of transport of cefadroxil through ELM process

\section{Results And Discussion}

The feed phase used for the transport studies of the cefadroxil was aqueous hydrochloric acid solution, the hydrochloric acid concentration was varied from $0.01 \times 10^{-2}$ to $1.0 \mathrm{~mole} / \mathrm{dm}^{3}$. It was observed that percent transport of cefadroxil was maximum at $1 \times 10^{-2} \mathrm{~mole} / \mathrm{dm}^{3}$ of $\mathrm{HCl}$. As cefadroxil contains both $-\mathrm{COOH}$ and $\mathrm{NH}_{2}$ groups. Therefore it exists in ionic forms of different charges in solutions depending upon $\mathrm{pH}$ of the media and $\mathrm{pKa}$ values. At $\mathrm{pH}$ values below 4 it exists predominantly in cationic form whereas above $\mathrm{pH} 6$ it exists predominantly anionic form. When membrane is contacted with feed phase consisting cefadroxil cations the following equilibrium reactions take place in feed phase

$$
\begin{array}{ll}
\mathrm{RH} \leftrightarrow \mathrm{R}^{-}+\mathrm{H}^{+} & \text {where } \mathrm{RH} \text { is reagent } \\
\mathrm{X}+\mathrm{H}+\mathrm{R}-\rightarrow \mathrm{XHR} & \text { where } \mathrm{XH} \text { is molecule of cefadroxil }
\end{array}
$$

In membrane phase

$$
\mathrm{XHR}_{(\mathrm{a})} \leftrightarrow \mathrm{XHR}_{(\mathrm{O})}
$$

In internal phase

$$
\mathrm{XHR}_{(\mathrm{a})}+\mathrm{H}+\rightarrow \mathrm{XH}+\mathrm{RH}
$$

RH produced is regenerated into the membrane and the process is continued till all cefadroxil transports. Thus the mode of mechanism of transport process of cefadroxil is facilitated coupled co-ransport. Internal phase used for transport of cefadroxil was $1.0 \mathrm{~mole} / \mathrm{dm}^{3}$ of $\mathrm{NaCl}$ in carbonate buffer, variation in the $\mathrm{pH}$ of this solution were studied from 6 to 10 ,it was observed that percent transport was maximum at $\mathrm{pH} 9$ and therefore $\mathrm{pH}$ of the internal phase was fixed at 9. The presence of chloride ions prevent membrane swelling, variation in the concentration of $\mathrm{NaCl}$ showed $1.0 \mathrm{~mole} / \mathrm{dm}^{3}$ was sufficient to give maximum percent transport of cefadroxil. Chloride ion present in the internal phase produce a concentration gradient between the two phases hence act as a driving force to transport cefadroxil.

The stirring time of transport was carried out from 5 to 35 minutes keeping all other parameters constant. It was observed that percent transport of cefadroxil was found to increase with increase in time of stirring from 5 to 25 minutes and remained constant thereafter. Therefore, a stirring time of 25 minutes was used as optimum time of stirring. The natural logarithm of the ratio of initial concentration [ $\mathrm{Co}$ ] to the given time 
[Ct] of cefadroxil in feed phase was varied for 5 to 25 minutes and $\mathrm{In} \mathrm{Co} / \mathrm{Ct}$ against time of stirring $\mathrm{t}$ in seconds were plotted. These graphs were straight lines showing transport of cefadroxil is a first order reaction with $0.0003 \mathrm{sec}^{-1}$ as transfer rate constant.

Variation in the concentration of carrier used for the preparation of membranes from 5 to $20 \%$ in toluene, indicate that the percent transport of cefadroxil increases with increase in carrier concentration and found to be maximum at $10 \%(\mathrm{v} / \mathrm{v})$, therefore carrier concentration $10 \%(\mathrm{v} / \mathrm{v})$ was selected for further studies. As the carrier concentration in the membrane increases initial flux increases hence percent transport increases. However, too much increase in the carrier concentration increases the viscosity of the membrane thereby decreasing the transport. Variation in the surfactant span-80 concentration from 6 to $16 \%$ ( v/v) was carried out, it was seen that $13 \%(\mathrm{v} / \mathrm{v})$ span-80 was sufficient a the maximum transport of cefadroxil and membrane stability. Therefore, $13 \%(\mathrm{v} / \mathrm{v})$ span- 80 was used in the preparation of emulsion.For the preparation of emulsion membranes the reagent should be taken in different organic solvents depending upon their solubilities. In present work different solvents such as kerosene, toluene, hexane and dichloromethane were used. It was found that the percent transport of cefadroxil were maximum when membrane solvent used was toluene. Therefore toluene was used as membrane solvent. The stirring rate (speed of agitation) affects the performance of ELM process to great extent. Therefore its effect on the \% transport is very important. Variation of stirring rate from 100 to 500 rotation per minute $(\mathrm{rpm})$ in present showed that percent transport of cefadroxil increased with increase in stirring rate up to 300rpm and decreased above this rate, Increase in speed should increase the mass transfer. However, in the present case the percent transport decreased above 300rpm on the contrary to the general expectation this may be attributed to hydrodynamic instability of ELM at high speed causing sheer on the emulsion globules resulting its breakage.

Table -1Various parameters for the extraction of cefadroxil

\begin{tabular}{|l|l|l|l|}
\hline Parameters & Various conditions applied & Optimum condition & Recovery $(\%)$ \\
\hline Feed phase concentration & $0.01 \times 10^{-2}-1.0 \mathrm{~mole} / \mathrm{dm}^{3}$ & $1 \times 10^{-2} \mathrm{~mole} / \mathrm{dm}^{3}$ & \\
\cline { 1 - 2 } Internal phase $\mathrm{pH}$ & $6-10$ & $\mathrm{pH}=9$ & \multirow{3}{*}{$80.64 \%$} \\
\hline Reagent concentration(\% v/v) & $4-14(\% \mathrm{v} / \mathrm{v})$ & $10 \% \mathrm{v} / \mathrm{v}$ & \\
\hline Stirring speed(rpm) & $100-500 \mathrm{rpm}$ & $300 \mathrm{rpm}$ & \\
\hline Stirring time(minutes) & $5-35 \mathrm{minutes}$ & 20 minutes & \\
\hline Surfactantconcentration $(\% \mathrm{v} / \mathrm{v})$ & $6-16(\% \mathrm{v} / \mathrm{v})$ & $13(\% \mathrm{v} / \mathrm{v})$ & \\
\hline Solvents & Kerosene,dichloromethane, hexane,toluene & toluene & \\
\hline
\end{tabular}

Table 2 Table of recovery of cefadroxil from synthetic mixture

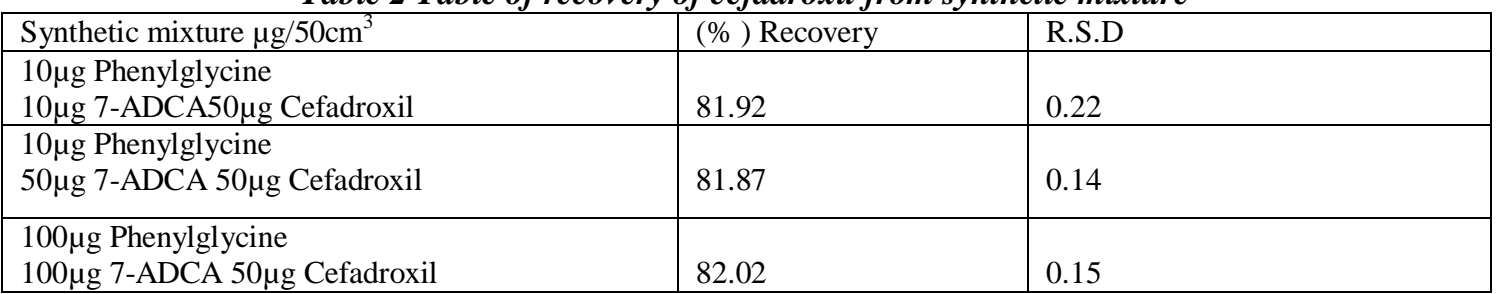

\section{Application Of The Method For The Separation Of Cefadroxil From Synthetic Mixture}

Application of the proposed method of transport of cefadroxil using cyanex-301 as developed above has been tested for its suitability for the recovery of cefadroxil from a synthetic mixture of the effluent sample of cefadroxil synthesis. Effluent sample of cefadroxil is associated with phenylglycine hydrochloride and 7aminodeacetoxy cephalosporanicacid (7ADCA).Therefore, variousamountsofphenylglycinehydrochloride and 7-ADCA were taken with the fixed amount of cefadroxil and the transport studies were carried out by the procedure developed as above. It was observed that the present method can be satisfactorily applied for the recovery of cefadroxil from the waste mixture.

\section{References:}

[1] Kwi Ho Lee Sang Cheol Lee \& Won Kook Lee, J.Chem.Tech.Biotech, , 59, (1994),371.

[2] H.Itoh, M.P.Thien, T.A.Hatton \& D.I.C.Wang, Biotech. \& Bioeng, 35 ,(1990), 853.

[3] Sahoo G.C, Dutta N.N, J.Mem.Sci, 15, (1998), 145.

[4] C.Scholler, Chaudhari J.B. \& Pyle D.P., Biotech. \& Bioeng, 42 ,(1993) ,50.

[5] Mok, Y.S.; Lee S.C.; Lee, Separation Science \& Technology, 30,(1995), 217.

[6] Hagg M.B., Sep.Purification Methods, 27, (1998), 51.

[7] Mishra B.M. \& V.Ramchandran, J.Surf.Sci.Technol, 14 (1998), 235. 